2001s-17

\title{
A Theory of Environmental Risk Disclosure
}

Bernard Sinclair-Desgagné, Estelle Gozlan

\section{Série Scientifique \\ Scientific Series}

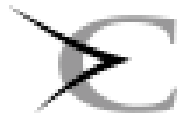




\section{CIRANO}

Le CIRANO est un organisme sans but lucratif constitué en vertu de la Loi des compagnies du Québec. Le financement de son infrastructure et de ses activités de recherche provient des cotisations de ses organisationsmembres, d'une subvention d'infrastructure du ministère de la Recherche, de la Science et de la Technologie, de même que des subventions et mandats obtenus par ses équipes de recherche.

CIRANO is a private non-profit organization incorporated under the Québec Companies Act. Its infrastructure and research activities are funded through fees paid by member organizations, an infrastructure grant from the Ministère de la Recherche, de la Science et de la Technologie, and grants and research mandates obtained by its research teams.

\section{Les organisations-partenaires / The Partner Organizations}

-École des Hautes Études Commerciales

-École Polytechnique

-Université Concordia

-Université de Montréal

-Université du Québec à Montréal

-Université Laval

-Université McGill

-MEQ

-MRST

-Alcan Aluminium Ltée

-AXA Canada

-Banque du Canada

- Banque Laurentienne du Canada

-Banque Nationale du Canada

-Banque Royale du Canada

-Bell Québec

-Bombardier

-Bourse de Montréal

-Développement des ressources humaines Canada (DRHC)

-Fédération des caisses populaires Desjardins de Montréal et de l'Ouest-du-Québec

-Hydro-Québec

-Imasco

-Industrie Canada

-Pratt \& Whitney Canada Inc.

-Raymond Chabot Grant Thornton

-Ville de Montréal

(C) 2001 Bernard Sinclair-Desgagné et Estelle Gozlan. Tous droits réservés. All rights reserved.

Reproduction partielle permise avec citation du document source, incluant la notice $\odot$.

Short sections may be quoted without explicit permission, if full credit, including $\odot$ notice, is given to the source.

Ce document est publié dans l'intention de rendre accessibles les résultats préliminaires

de la recherche effectuée au CIRANO, afin de susciter des échanges et des suggestions.

Les idées et les opinions émises sont sous l'unique responsabilité des auteurs, et ne représentent pas nécessairement les positions du CIRANO ou de ses partenaires.

This paper presents preliminary research carried out at CIRANO and aims at encouraging discussion and comment. The observations and viewpoints expressed are the sole responsibility of the authors. They do not necessarily represent positions of CIRANO or its partners. 


\title{
A Theory of Environmental Risk Disclosure*
}

\author{
Bernard Sinclair-Desgagné $e^{\dagger}$ Estelle Gozlan ${ }^{*}$
}

\section{Résumé / Abstract}

La réglementation des risques environnementaux met de plus en plus l'accent sur l'information et la responsabilisation des parties prenantes. Le succès de cette approche repose toutefois largement sur la qualité de l'information fournie par les entreprises visées. Cet article porte sur la quantité et la qualité de l'information qui serait volontairement fournie à une partie prenante par un pollueur potentiel. On trouve que cette information sera moins précise lorsque la partie prenante est confiante (voire naïve) a priori, que le coût d'analyse de l'information livrée croît avec la complexité de celle-ci, ou que le revenu attendu par une entreprise se révélant être en non conformité est petit. En revanche, une partie prenante inquiète et un faible coût de production de données précises encouragent la livraison d'une information de meilleure qualité. La précision de l'information livrée permet à une firme sûre de se distinguer d'autant plus facilement d'une firme dangereuse que son revenu ex post est relativement plus élevé. À la lumière de notre modèle, on examine en terminant plusieurs principes se rapportant au design des programmes publics de révélation des risques à la santé et à l'environnement.

The regulation of environmental risks increasingly emphasizes the awareness and empowerment of stakeholders. The success of this approach, however, seems to depend crucially on the quality of environmental disclosures. In this paper we investigate the amount and quality of the information that would be voluntarily delivered to some stakeholder by a potential polluter. We find that information may be hazier when the stakeholder is confident (or naive) a priori, the cost of analyzing the received reports increases little with their complexity, or a polluter's net expected payoff from undertaking an industrial activity that would turn out to be unsafe is small. A worried stakeholder and a low cost of producing more accurate figures, on the other hand, may favor disclosure of high-quality information. By delivering information of very good quality, safe firms can set themselves apart more easily from the dangerous ones the higher the relative ex

\footnotetext{
* Corresponding Author: Bernard Sinclair-Desgagné, CIRANO, 2020 University Street, $25^{\text {th }}$ floor, Montréal, Qc, Canada H3A 2A5 Tel.: (514) 985-4010 Fax: (514) 985-4039 email: bsd@cirano.qc.ca We are grateful to Bruno Biais, Peter Bogetoft, Nathalie Dierkens, Steve Hansen, Steven Huddart, Murgie Krishnan, Stéphan Marette, Eric Noreen, Eric Rasmusen, Ariel Rubinstein, Kathy Segerson, Tom Tietenberg and Bob Winkler for valuable discussions on the topic of this paper. We also wish to thank seminar participants at INSEAD, HECParis, Stanford, and the University of Connecticut for their comments on earlier drafts. Estelle Gozlan gratefully acknowledges financial support from the NSERC Industrial Chair in Site Remediation and Management at École Polytechnique de Montréal.

† École Polytechnique de Montréal et CIRANO

\# École Polytechnique de Montréal, INRA et CIRANO
} 
post payoff from their current industrial activity. The implications of this framework for the scope and design of public programs of environmental disclosure are briefly examined.

Mots Clés: Approche informationnelle de la réglementation, jeux de signaux, jeux de persuasion, études d'impact environnemental

Keywords: Environmental reporting, signalling, persuasion, informational regulation JEL: I18, D82, C72 


\section{INTRODUCTION}

The regulation of industrial risks to human health and the environment relies increasingly on making the relevant information available to all interested parties. Examples of recent actions in this direction include government-sponsored right-to-know programs, SEC rules that environmental liabilities and risks be publicly disclosed, blacklisting of notorious polluters by non-governmental organizations, and the spreading corporate practice of voluntary environmental reporting. It is widely believed that such measures constitute an effective and efficient way to have polluters internalize the potential harms they might inflict on third parties ${ }^{1}$. For most firms naturally seek the goodwill of neighboring communities, employees, shareholders, financial institutions, local governments and citizens in general, especially if losing that goodwill can bear significant financial consequences. Furthermore, enabling all stakeholders to actively participate in enforcing environmental regulation may also lower the administrative and political costs of enforcement.

To be successful, however, a regulation of industrial risks based on information disclosure calls for at least two preconditions. First, the interested parties must have the ability to act quickly and wisely on the basis of the information they receive. This means in particular that potential victims and stakeholders can access the judicial system at a reasonable cost and that the latter is effective in bringing noncompliant polluters back into compliance. Several authors have indeed emphasized the "institutional complementarity" between informational regulation on the one hand and the legal empowerment of private parties on the other (see, e.g., Tietenberg and Wheeler [24]). Second, the information provided must also be of reasonably good quality, considering the costs associated with producing, disseminating and processing data. From a public policy perspective this raises a number of positive and normative questions concerning, for instance, the accuracy of firm-specific information that would be voluntarily disclosed, the level of information provision that would be socially desirable, and the appropriate extent of mandatory standards for environmental risk disclosure. This paper seeks to address these questions.

Our theoretical study confronts a potential polluter (say a firm) with some typical stakeholder (say an activist organization). The former may gather and disclose more or less precise data documenting the impact of his activity on human health and the environment. The latter may approve or boycott the activity, given the a priori information she already has and the quality of the additional (firmspecific) data she receives. This thought-experiment is cast into a simple game of incomplete information which combines features of signalling games (see, for instance, Fudenberg and Tirole [10]) and of persuasion games (see, for instance, Milgrom [17]). The figures disclosed first act as a strategic signal of whether or not the activity entails significant hazards to human health and the environment. At the same time, however, the supplied data convey substantive information concerning the activity itself : in a decision-theoretic sense they provide one further test that the

\footnotetext{
1 The main rationales for this so-called "informational regulation" are presented and discussed in Kleindorfer and Orts [15], Tietenberg and Wheeler [24], and Sinclair-Desgagné [21]. There is also a young and growing literature that centers on the effectiveness of public environmental disclosures in various countries (see, e.g., Afsah, Laplante and Wheeler [1], Bui and Mayer [3], Khanna, Quimio and Bojilova [13, 14], and the current survey by Tietenberg and Wheeler [24]).
} 
stakeholder can use, if she deems it useful, to update her subjective risk assessment. This test would of course be subject to type I (suggesting to boycott an otherwise safe activity) and type II (recommending approval of a truly dangerous activity) errors. The probability of not making such errors, which is usually referred to as the accuracy or precision of the data, formally captures the quality of the released information.

The accounting and economics literatures offer a number of alternative models of disclosure ${ }^{2}$. Our model deals neither with endogenous asymmetric information (unlike De Groote [7]), nor with costless, nonbinding, non-verifiable communication or cheap talk (unlike Crawford and Sobel [5]), nor with situations where the cost of disclosure is endogenous (unlike Wagenhofer [28]), nor finally with competing information channels (unlike Diamond [6]). However, it embodies some central propositions of those literatures whilst portraying important elements of environmental risk disclosure. One such element is the fact that voluntary reports on the hazards of complex products or processes convey strategic intentions (i.e. constitute a signal) as well as hard information. Another one is that industrial risk assessments must often rely on key firm-specific data that only the potential polluter himself can deliver. Lastly, the quality of voluntarily disclosed environmental information is largely demand-driven and dependent upon commonly-known characteristics of the stakeholder, such as whether she holds a positive or a negative view of the industrial activity, whether and at what cost she can make sense of the data she receives, and whether she has the ability to pin down any misleading information.

In the upcoming sections we argue that no additional information would be voluntarily provided to a confident stakeholder who would readily (and perhaps naively) endorse the activity. This situation justifies government intervention that could take the form of mandatory disclosures or of an advertisement campaign to increase public awareness. For a worried stakeholder who openly and credibly leans towards a boycott may succeed in getting additional data from the potential polluter. If only truthful information can be disclosed in this case, then the equilibrium under some circumstances is a pooling one in which reports associated with a safe or with a dangerous activity convey the same moderately-accurate data ${ }^{3}$. The quality of information will then be just high enough to prompt the stakeholder to make one further test based on the received data before taking action. Under opposite circumstances, however, the equilibrium is rather a separating one in which reports surrounding a safe industrial activity are so detailed and thus expensive that they cannot possibly be imitated by a firm dealing with a noxious activity. Whether this outcome is socially preferable to the previous one will be shown to depend on the firm's cost of disclosure and the stakeholder's cost of analyzing data: under separation, only the firm engaged in the safe activity bears the cost of providing high-quality data; in the pooling case, however, each firm pays a relatively lower price for delivering moderately-precise information but the stakeholder must bear the cost of analyzing it.

The paper is organized as follows. The following section contains a description of the basic model.

\footnotetext{
${ }^{2}$ Representative earlier works include Bowden [2], Dye [8], Hughes [12], Trueman [26], and Verrecchia [27].

3 As shown in section 3, this equilibrium satisfies the so-called "intuitive criterion" of Cho and Kreps [4].
} 
Section 3 presents the main results and their interpretation. Section 4 compares these results with those in the existing literature on disclosure. Section 5 discusses several extensions and additional policy implications of the model. Section 6 concludes.

\section{THE RISK DISCLOSURE GAME}

In the standard decision-theoretic framework, a decision-maker who faces uncertain prospects may choose to act right away or to postpone a decision until additional evidence has been gathered and processed. The latter usually amounts to using an imperfect test characterized by a probability $\beta$ that its recommendation would match the decision-maker's best interest (1- $\beta$ is thus the probability that the test's conclusion would be misleading). This probability, which measures the precision or accuracy of the test, captures in a certain way the quality of the available data. The present model simply amends this framework by letting an opportunistic agent set $\beta$.

The outcome is the game pictured in figure 1. In this game a potential polluter (say a firm, $\mathscr{F}$ ) faces a stakeholder (say an activist organization, $\mathscr{Q}$ ) who may approve or boycott his activity. The former knows whether this activity would eventually turn out to be harmful (i.e. dangerous) or not (i.e. safe); the latter, however, only holds prior beliefs represented by the probability $\mu<1$ that the activity is safe.

\section{Insert Fig. 1 about here.}

The sequence of decisions by the two players is now as follows. First, the informed firm delivers an environmental report characterized by a level of precision $\beta \in[0,1]$. Upon seeing this report, the stakeholder may immediately approve (y) or boycott (n) the firm's activity, or she may decide instead to carefully study (test) the report before committing herself. The parameter $\beta$ determines whether an examination of the supplied report will yield faithful conclusions - i.e., testing "negative" (-) when there is indeed nothing to fear and "positive" (+) when the activity constitutes a real threat. After reaching those conclusions, the stakeholder must finally decide to approve or boycott the firm's activity.

The firm who produces and disseminates data of accuracy $\beta$ bears a cost $f(\beta)$. An immediate boycott yields status quo incomes to the firm and the stakeholder that are both normalized at 0 . Early approval, on the other hand, yields the firm positive incomes $M>0$ and $Z>0$ if the activity is respectively safe or dangerous, while the stakeholder achieves a "good" payoff G $>0$ under a safe activity but a "bad" payoff B < 0 under a dangerous one. When she rather uses the supplied report as a test and studies it thoroughly, the stakeholder incurs a cost $t(\beta)$ that varies upon the complexity of the investigated figures (which $\beta$ reflects). We make the following assumptions concerning the 
firm's and the stakeholder's respective cost functions ${ }^{4}$ :

- $f(\cdot)$ and $t(\cdot)$ are nonnegative and strictly convex on $[0,1]$.

○ $f(0.5)=0$ and $t(0.5)=0$.

- $f(1) \geq \max \{M, Z\}$.

- $f(\beta)=f(1-\beta)$ and $t(\beta)=t(1-\beta)$.

The first assumption says that the marginal cost of precision is strictly increasing. The second one means that any firm can afford the least informative reports (i.e. reports that are as instructive as the toss of a fair coin). The third one implies that fully accurate reports are too expensive to produce and disseminate. The last one states, finally, that a report explaining peculiar attributes with some accuracy would be as expensive to produce and to study as one conveying the opposite attributes with the same precision.

In this context a (pure) strategy for the firm is a function $\beta:\{$ safe, dangerous $\} \rightarrow[0,1]$ mapping the actual nature of the activity into a disclosure quality level. Similarly, the stakeholder's (pure behavioral) strategy is made of two rules that map received messages into actions, that is :

$\mathrm{K}_{1}:[0,1] \rightarrow\{$ approve, boycott, test $\}$ at the nodes where the report is received, and

$\mathrm{K}_{2}:\{-,+\} \rightarrow\{$ approve, boycott $\}$ at the nodes following the conclusion of a test.

The fact that the stakeholder may remain uncertain about the dangers inherent in the industrial activity is indicated by the dotted lines; the decision nodes linked together by such lines form the stakeholder's information sets. At the time she must choose what to do, the stakeholder may not be able to distinguish between two different nodes in the same information set. She always holds a subjective probability distribution over those sets, however. This distribution would of course take into account the messages received, using Bayes's rule wherever possible. After getting a report of precision $\beta$, for instance, the stakeholder believes the activity is safe with probability

$$
\mu_{1}(\beta)=\mathrm{P}(\text { safe } \mid \beta)=\mu \mathrm{P}(\beta \mid \text { safe }) /[\mu \mathrm{P}(\beta \mid \text { safe })+(1-\mu) \mathrm{P}(\beta \mid \text { dangerous })]
$$

This subjective probability is updated further to

$$
\begin{aligned}
& \mu_{2}(-)=\mathrm{P}(\text { safe } \mid-)=\mu_{1} \beta /\left[\mu_{1} \beta+\left(1-\mu_{1}\right)(1-\beta)\right] \\
& \left.\mu_{2}(+)=\mathrm{P}(\operatorname{safe} \mid+)=\mu_{1}(1-\beta) /\left[\mu_{1}(1-\beta)+\left(1-\mu_{1}\right) \beta\right)\right]
\end{aligned}
$$

\footnotetext{
4 Any properly scaled, strictly decreasing and concave transformation of the entropy functions of information theory would satisfy these assumptions. The players' costs are thereby made proportional to the "informational content" of reports, in a precise sense.
} 
when the report is analyzed and a negative (2a) or positive (2b) conclusion is reached.

The description of the game is now complete. The following section presents and discusses the main results of the paper.

\section{MAIN RESULTS}

The propositions of this section describe some perfect Bayesian equilibria (PBE) of the risk disclosure game. Roughly speaking, a PBE is a pair of strategies $\left[\beta(\cdot) ;\left(\mathrm{K}_{1}(\cdot), \mathrm{K}_{2}(\cdot)\right)\right]$ such that ${ }^{5}$ :

(i) strategy $\beta(\cdot)$ maximizes the firm's expected payoff, given the stakeholder's strategy $\left(\mathrm{K}_{1}(\cdot), \mathrm{K}_{2}(\cdot)\right)$;

(ii) strategy $\left(\mathrm{K}_{1}(\cdot), \mathrm{K}_{2}(\cdot)\right)$ maximizes the stakeholder's expected payoff, given the potential polluter's strategy $\beta(\cdot)$ and the stakeholder's current beliefs about the harmlessness of the industrial activity;

(iii) the beliefs $\mu, \mu_{1}, \mu_{2}$ are obtained successively using Bayes's rule, whenever feasible.

It is not possible, however, to get $\mu_{1}$ through Bayes's rule when the observed precision level, say $\beta^{\prime}$, is inconsistent with the given equilibrium strategy, because in this case $\mathrm{P}\left(\beta^{\prime} \mid\right.$ safe $)$ and $\mathrm{P}\left(\beta^{\prime} \mid\right.$ dangerous $)$ must both be zero by definition of an equilibrium. We deal with this well-known problem by first assuming that the stakeholder will then set her beliefs via forward induction. Under this mode of reasoning, the stakeholder views any action by the potential polluter as intentional (as opposed to being the result of some mistake or some technological failure). She thus rules out safety levels at which, ex ante, the firm would never deliver a report of quality $\beta^{\prime}$. Once her beliefs are updated accordingly, we shall furthermore require that the stakeholder's payoff-maximizing reaction be able to deter any such "surprising" (i.e. out-of-equilibrium) accuracy level".

The equilibria obtained in this manner turn out to be unique modulo two characteristics of the stakeholder which are defined as follows.

Definition 1. The stakeholder is said to be confident if ex ante she holds a strictly positive expected payoff, i.e. if $\mu \mathrm{G}+(1-\mu) \mathrm{B}>0$. Otherwise, the stakeholder is said to be worried.

Definition 2. The stakeholder is called clairvoyant if she can distinguish between accuracy levels $\beta$ and 1- $\beta$. She is called quasi-clairvoyant when she can only distinguish between accuracy levels that entail different costs of analysis (in other words, she confuses information of precision $\beta$ with information of precision $1-\beta)$.

\footnotetext{
5 See Fudenberg and Tirole [10] for a rigorous definition and complete discussion of perfect Bayesian equilibrium and its refinements.

6 This amounts formally to satisfying the "intuitive criterion" of Cho and Kreps [4].
} 
The following subsections now consider the cases of a confident stakeholder and of a worried but quasi-clairvoyant stakeholder respectively. These cases will act as benchmarks for the upcoming policy discussion.

\subsection{The confident stakeholder}

A confident stakeholder endorses the industrial activity a priori. It is therefore a dominant strategy for the potential polluter in this case to set $\beta(\cdot) \equiv 0.5$. This readily supports our first result.

PROPOSITION 1. Suppose that the stakeholder is confident. Then, at the equilibrium, the potential polluter always selects an accuracy level of 0.5 and the stakeholder approves the industrial activity.

Proof. It is clearly optimal for the potential polluter to set $\beta(\cdot) \equiv 0.5$ when the stakeholder approves his activity at once. On the other hand, if $\beta$ (safe $)=\beta$ (dangerous) $=0.5$, then the stakeholder's beliefs (on the equilibrium path) remain constant since

$$
\begin{gathered}
\mu_{1}=\mu \mathrm{P}(0.5 \mid \text { safe }) /[\mu \mathrm{P}(0.5 \mid \text { safe })+(1-\mu) \mathrm{P}(0.5 \mid \text { dangerous })]=\mu \cdot 1 /[\mu \cdot 1+(1-\mu) \cdot 1]=\mu \\
\text { and } \mu_{2}(\cdot) \equiv \mu_{1} 0.5 /\left[\mu_{1} 0.5+\left(1-\mu_{1}\right) 0.5\right]=\mu .
\end{gathered}
$$

The stakeholder's payoff from an immediate boycott is 0 . And her net expected income from undertaking a test based on the current report is also

$$
\begin{aligned}
& \mathrm{P}(-) \max \left[0, \mu_{2}(-) \mathrm{G}+\left(1-\mu_{2}(-)\right) \mathrm{B}\right]+\mathrm{P}(+) \max \left[0, \mu_{2}(+) \mathrm{G}+\left(1-\mu_{2}(+)\right) \mathrm{B}\right] \\
& =[\mu 0.5+(1-\mu)(1-0.5)](\mu \mathrm{G}+(1-\mu) \mathrm{B})+[\mu(1-0.5)+(1-\mu) 0.5](\mu \mathrm{G}+(1-\mu) \mathrm{B}) \\
& =\mu \mathrm{G}+(1-\mu) \mathrm{B} .
\end{aligned}
$$

It is therefore optimal for the stakeholder to approve the industrial activity right away ${ }^{7}$.

Although the formal treatment of this case is rather straightforward, it yields interesting policy conclusions. For the potential polluter, delivering a report of precision 0.5 is the practical equivalent of not providing any useful information. Mandating some disclosure might be appropriate in this case, if one deems the stakeholder to be naïve or ill-informed. As we will now see, however, a valuable alternative to this approach would also be to instill doubts in the stakeholder's mind.

\footnotetext{
${ }^{7}$ Discussing out-of-equilibrium beliefs and best responses is unnecessary here.
} 


\subsection{The worried stakeholder}

A worried stakeholder needs to be convinced before approving the industrial activity. This attitude puts pressure on the firm to produce and deliver useful data. Two mutually exclusive outcomes may now occur. A firm handling a safe activity and one dealing with real hazards may either both disclose information of the same accuracy - this is the so-called pooling equilibrium, or the quality of their respective report may differ - which is the so-called separating equilibrium. In the first case, the stakeholder who is initially skeptical will change her mind only after the conclusion of an ultimate test increases sufficiently the likelihood that the industrial activity is safe. In the second case, the worried stakeholder knows right upon observing the quality of the information delivered whether or not the current industrial activity is safe. These two outcomes clearly bear different social costs. Which one prevails, however, will be shown to depend on parameters of the model that the regulator can control.

For the time being, let us suppose that the stakeholder is quasi-clairvoyant, the range of $\beta(\cdot)$ is restricted to the interval $[0.5,1]$, and $\mathrm{M}$ is strictly greater than $\mathrm{Z}$. These assumptions will be lifted in section 5. The latter could depict a situation where the dangerous firm faces significant (uninsurable) penalties ex post. The second one may capture the fact that the disclosed data are verifiable, so the potential polluter cannot propose a misleading test. This context yields an intuitive construction of the equilibrium of the game. Let us start with the following statement.

LEMMA TO PROPOSITION 2. Suppose that the stakeholder studies the report. Then $(i) \mu_{1}=\mu$; and (ii) the stakeholder approves the activity if and only if the report tests "negative", i.e.

$K_{2}(-)=$ "approve" and $K_{2}(+)=$ "boycott" .

Proof. (i) The stakeholder needs to study a report only if she cannot distinguish right away a safe from a dangerous activity. Since she is quasi-clairvoyant and $\beta(\cdot) \in[0.5,1]$, this can only occur when $\beta($ safe $)=\beta($ dangerous $)=\beta$. In this case we have $P(\beta \mid$ safe $)=P(\beta \mid$ dangerous $)$ by definition. Hence, $\mu_{1}=\mu$ by rule $(1)$.

(ii) First note that the stakeholder would not study the report if her strategy were such that $\mathrm{K}_{2}(-)=\mathrm{K}_{2}(+)=$ "boycott" or $\mathrm{K}_{2}(-)=\mathrm{K}_{2}(+)=$ "approve", for her expected payoff would then be respectively $-\mathrm{t}(\beta) \leq 0$ or $\mu \mathrm{G}+(1-\mu) \mathrm{B}-\mathrm{t}(\beta) \leq 0$. It must therefore be the case that either $\mathrm{K}_{2}(-)=$ "approve" (and then $\mathrm{K}_{2}(+)=$ "boycott") or $\mathrm{K}_{2}(-)=$ "boycott" (and so $\mathrm{K}_{2}(+)=$ "approve"). By the first part, the stakeholder's expected payoff from $\mathrm{K}_{2}(-)=$ "approve" is $\mu \beta \mathrm{G}+$ $(1-\mu)(1-\beta) B-t(\beta)$, whilst that from $K_{2}(-)=$ "boycott" is $\mu(1-\beta) G+(1-\mu) \beta B-t(\beta)$. Clearly, $K_{2}(-)=$ "approve" is the better strategy when $\beta \geq 0.5$.

Figure 2 now shows the potential polluter's revenues and costs according to the chosen precision level, the type of industrial activity and the stakeholder's decision: the horizontal straight lines correspond to immediate approval by the stakeholder, whilst the positively and negatively sloped lines give the firm's expected payoff when the delivered report is studied and the firm's activity is 
respectively safe or dangerous. The Figure also exhibits three important thresholds.

\section{Insert fig. 2 about here.}

The first one, named $\beta_{0}$, satisfies the equation $\mathrm{Z}-\mathrm{f}(\beta)=0$; a firm dealing with hazardous products and processes cannot afford producing data of accuracy higher than or equal to $\aleph_{0}$. The second one, noted $\beta_{1}$, maximizes the function $[B M-f(ß)]$, which is the firm's expected profit if the industrial activity is safe and the stakeholder approves the industrial activity when the report tests "negative". Finally, $\beta_{2}$ is the smallest number in the interval $[0.5,1]$ that satisfies the inequalities

$$
\begin{aligned}
& \mu \beta G+(1-\mu)(1-\beta) B-t(B) \geq 0, \\
& -(1-\mu) ß B-\mu(1-\beta) G-t(B) \geq 0 .
\end{aligned}
$$

When $\mu_{1}=\mu$ and these inequalities hold, the stakeholder would prefer to study the report rather than to respectively boycott or approve the industrial activity right away.

Let $\beta_{3}=\max \left\{\beta_{1}, \beta_{2}\right\}$. We shall suppose that the thresholds satisfy the following:

- $\quad \beta_{3}<\beta_{0}$ and conditions (3) and (4) are fulfilled for any $\beta \in\left[\beta_{3}, \beta_{0}\right]$.

$\circ \quad\left(1-\beta_{3}\right) Z>f\left(\beta_{3}\right)$.

The latter assumption entails that the firm whose current activity is dangerous can afford disclosures that the stakeholder would deem to be worth studying. The former implies that the stakeholder would first choose to "test" when a reasonable amount of information is disclosed but the nature of the industrial activity remains ambiguous.

The equilibrium that finally emerges rests on whether or not we have

$$
\beta_{3} M-f\left(\beta_{3}\right)<M-f\left(\beta_{0}\right) \text {. }
$$

When (5) is true, it will be shown that the firm whose activity is safe chooses to signal this by providing very accurate (and expensive) information. When (5) does not hold, however, the potential polluter delivers moderately precise data that the stakeholder analyzes before taking action.

PROPOSITION 2. (i) Separating equilibrium: If (5) is satisfied, then the equilibrium has $\beta($ safe $)=\beta_{0}, \beta$ (dangerous $)=0.5$ and $K_{l}\left(\beta_{0}\right)=$ "approve", $K_{l}(0.5)=$ "boycott."

(ii) Pooling equilibrium: If the reverse inequality holds strictly in (5), then the equilibrium has $\beta($ safe $)=\beta$ (dangerous $)=\beta_{3}$ and $K_{1}\left(\beta_{3}\right)=$ "test" .

Proof. (i) Let $\beta_{4}$ be the unique number in $[0.5,1]$ such that $\left(1-\beta_{4}\right) \mathrm{Z}=\mathrm{f}\left(\beta_{4}\right)$. And consider now the

${ }^{8}$ Pooling and separation are both possible equilibria when (5) holds as an equality. 
following beliefs and moves by the stakeholder.

- For $\beta \in\left(\beta_{0}, 1\right], \mu_{1}(\beta)=1$ so $K_{1}(\beta)=$ "approve", the rationale being that only the firm dealing with a safe activity can afford producing information of this quality.

- For $\beta \in\left(\beta_{4}, \beta_{0}\right), \mu_{1}(\beta)=\mu$ so $K_{1}(\beta)=$ "test", because the firm dealing with an unsafe activity can also deliver such data and studying the report is the stakeholder's best action in this case.

- For $\beta \in\left(0.5, \beta_{4}\right), \mu_{1}(\beta)=0$ so $K_{1}(\beta)=$ "boycott", because such a deviation, if it were followed by a test, would benefit only the unsafe firm? .

Given these (out-of-equilibrium) beliefs and moves, and if condition (5) holds, the firm's and the stakeholder's respective actions described in the proposition clearly are best responses to one another when the stakeholder's beliefs $\mu_{1}(0.5)=0$ and $\mu_{1}\left(\beta_{0}\right)=1$ are obtained via Bayes's rule.

(ii) The equilibrium lays similarly on the following (out-of-equilibrium) beliefs and moves by the stakeholder.

- $\quad$ For $\beta \in\left(\beta_{0}, 1\right], \mu_{1}(\beta)=1$ so $\mathrm{K}_{1}(\beta)=$ "approve."

- For $\beta \in\left(\beta_{3}, \beta_{0}\right), \mu_{1}(\beta)=\mu$ so $K_{1}(\beta)=$ "test", because the firm dealing with an unsafe activity can also deliver such data and studying the report is the stakeholder's best action in this case.

- For $\beta \in\left(\beta_{2}, \beta_{3}\right), \mu_{1}(\beta)=0$ so $K_{1}(\beta)=$ "boycott", because such a deviation, if it were followed by a test, would benefit only the unsafe firm ${ }^{10}$.

- For $\beta \in\left(0.5, \beta_{2}\right), \mu_{1}(\beta)=\mu$ but $K_{1}(\beta)=$ "boycott", since the delivered information is then not precise enough to indicate whether the activity is safe nor to justify making a costly test.

Under the proposition's assumption, the stated actions for the firm and the stakeholder clearly are best responses to each other when the stakeholder's beliefs $\mu_{1}\left(\beta_{3}\right)=\mu$ are obtained using (1).

Figure 2 and the arguments of the proof allow some straightforward yet interesting comparative statics. First, a lower cost of analysis $\mathrm{t}(\beta)$ contributes to relax constraints (3) and (4), which brings $\beta_{2}$ (and thus $\beta_{3}$ ) down; this renders a pooling equilibrium and its lower precision level more likely. Perhaps surprisingly though, a lower delivery cost $\mathrm{f}(\beta)$ can also have the same effect, for it leaves the right-hand-side of (5) unchanged whilst the left-hand-side goes up because $\beta_{1}$ increases. If the initial equilibrium is already a pooling one, however, cheaper delivery always entails that the quality of reports is upgraded at the subsequent pooling equilibrium. A decrease in the return $\mathrm{Z}$ from the noxious activity, on the other hand, may raise the right-hand-side of (5) and thus the likelihood that the highly accurate reports associated with the separating equilibrium occur. If separation is already

9, 10 This is where the "intuitive criterion" of Cho and Kreps [4] bites. 
the outcome, however, it remains so but the quality of the information provided by the safe firm goes down. Finally, the overall impact of an increase in the payoffs B, G, M or in the subjective probability $\mu$ is ambiguous : higher $\mathrm{B}, \mathrm{G}$, or $\mu$ relax (3) but make (4) tighter, whilst a greater M raises both sides of inequality (5).

From a public policy standpoint the proposition also makes it clear that, perhaps contrary to conventional wisdom, more accurate information is not necessarily better. To see this, notice that the ex ante social benefit of a separating equilibrium is given by

$$
\mathrm{W}_{\text {sep }}=\mu\left[\mathrm{G}+\mathrm{M}-\mathrm{f}\left(\beta_{0}\right)\right] \text {, }
$$

whilst the one associated with a pooling equilibrium is equal to ${ }^{11}$

$$
\mathrm{W}_{\text {pool }}=\left[\mu \beta_{3}(\mathrm{G}+\mathrm{M})+(1-\mu)\left(1-\beta_{3}\right)(\mathrm{B}+\mathrm{Z})\right]-\mathrm{f}\left(ß_{3}\right)-\mathrm{t}\left(ß_{3}\right)
$$

Depending on the respective sizes of the payoffs $\mathrm{G}, \mathrm{B}, \mathrm{M}, \mathrm{Z}$ and on the behavior of the cost functions $\mathrm{f}(\cdot)$ and $\mathrm{t}(\cdot)$, both $\mathrm{W}_{\text {sep }}>\mathrm{W}_{\text {pool }}$ and $\mathrm{W}_{\text {sep }}<\mathrm{W}_{\text {pool }}$ are certainly possible. The higher accuracy brought by a separating equilibrium is therefore not always socially desirable.

Several other policy implications are discussed in section 5. Beforehand the following section will briefly position the above results within the literatures on disclosure and games of persuasion.

\section{RELATIONSHIPS WITH THE EXISTING LITERATURE}

The presence of the cost functions $\mathrm{f}(\cdot)$ and $\mathrm{t}(\cdot)$ clearly matters for the previous analysis. Without these, or equivalently if $\mathrm{f}(\cdot) \equiv 0$ and $\mathrm{t}(\cdot) \equiv 0$, our model would give way to the well-known "disclosure principle" of persuasion games (Grossman [11], Milgrom [17], Milgrom and Roberts [18], Okuno-Fujiwara, Postlewaite, and Suzumura [19]): if the stakeholder needs to be convinced, precision is costless, and the potential polluter cannot lie, then there is an equilibrium where the latter provides fully accurate information and reveals the true nature of his activity. This equilibrium would be supported by the usual "sophisticated-skepticism" argument that, in such a context, the stakeholder completely discounts any partial reporting because she believes that the firm dealing with a safe activity has no reason to conceal this.

Through propositions 1 and 2, however, our model encompasses another "classical" result due to Verecchia [27]: positive costs of reporting imply that vague disclosures do not necessarily signal a bad state of nature, for the specific payoff and cost structure can encourage a safe firm to reveal as little information as would a dangerous firm.

Reporting costs can easily be linked to the preparation and dissemination of data or to the proprietary

${ }^{11}$ The cost of making a type I error (boycotting a safe activity) does not appear in this formulation. 
nature of information. More specifically, the additional feature that the cost of reports increases with their accuracy makes it plausible to interpret the precision levels $\beta$ as measurements of an auditor's quality (or of the reliability of any outsider who assesses the environmental impact of the current industrial activity). Concerning the choice of auditor by an opportunistic firm, Titman and Trueman [25] argued earlier that the more benign the industrial activity the higher the quality of the auditor, whilst Hughes [12] showed that a firm's handling of a safe activity may not necessarily induce higher auditor quality if there are other means (e.g., ownership in the project) by which the firm could signal her goodwill. The above analysis brings these opposite conclusions together: according to proposition 2, cost and payoff functions that satisfy consition (5) induce a monotone relationship between harmlessness and audit quality, but functions inconsistent with that condition make the safe as well as the dangerous firm agree on their choice of auditor.

Our model does not address explicitly the timing of disclosures (unlike, for example, the models of Dye [8], Truman [26], and Teoh and Hwang [23]). As suggested by Verrecchia [27], however, one may assume that the cost of disclosure decreases with time. Proposition 2 and its comparative statics implications would now predict that reporting strategies which form a pooling equilibrium become more attractive but tend to deliver more precise data as time elapses. Once a pooling equilibrium is at sight, there is therefore an incentive for the regulator to postpone public hearings. But if it is the separating equilibrium that first shows up and turns out to be socially better, then the regulator will rather set a deadline at the last time $\mathrm{t}^{*}$ where $\mathrm{W}_{\text {pool }} \leq \mathrm{W}_{\text {sep }}$.

In a paper closely related to ours, Fishman and Hagerty [9] investigate the circumstances where it is desirable to limit further a potential polluter's discretion on disclosures. Our model is of course analogous to theirs but it takes precision as a continuous variable and, more importantly, brings in several traits of the stakeholder. This often yields complementary insights: for example, that a confident stakeholder renders voluntary disclosure unattractive, even to a firm handling a safe activity; and that if more precision is always desirable in the presence of a worried stakeholder, then less discretion might be granted to those potential polluters whose lower cost of data production tends to produce a pooling equilibrium.

Finally, a number of models have recently dealt with the cost of analyzing or acting upon the reports received. Shin [20], for instance, assumes the stakeholder is uncertain about the exact information possessed by the potential polluter. This feature is akin to quasi-clairvoyance, although the latter refers to uncertainty concerning the information delivered by the stakeholder. An advantage of using this notion in an environmental (by contrast to a financial) disclosure context is that, as we shall see in the next section, one can get meaningful results without having to make the extra assumption that the potential polluter never lies. Some costs of decision making are also brought up by Lewis and Poitevin [16], who deal with type I and Type II errors, and by Stocken [22], who allows specific retaliatory punishments in a repeated-game setting. Via the function $\mathrm{t}(\cdot)$ this paper rather emphasizes the cost of counter-expertise. This seems to make sense if one wants to examine informational regulation vis-à-vis environmental risks, for the empowerment of stakeholders that is thereby pursued hinges to a large extent on the affordability of independent experts. 


\section{FURTHER EXTENSIONS AND POLICY ISSUES}

Let us now examine what happens if some of the assumptions made in subsection 3.2 are relaxed. Suppose, first, that the range of $\beta(\cdot)$ is the whole interval $[0,1]$, or in other words that the potential polluter can deliver misleading information. Two outcomes are now possible. If the stakeholder is clairvoyant, then the assumed symmetry of the cost function $\mathrm{f}(\cdot)$ around 0.5 and arguments similar to those in the proof of proposition 2 yield four equilibrium candidates - the previous separating $\left[\beta(\right.$ safe $)=\beta_{0}, \beta$ (dangerous) $=0.5 ; \mathrm{K}_{1}\left(\beta_{0}\right)=$ "approve", $\mathrm{K}_{1}(0.5)=$ "boycott" $]$ and pooling ones $\left[\beta(\right.$ safe $)=\beta($ dangerous $)=\beta_{3} ; K_{1}\left(\beta_{3}\right)=$ "test" and $K_{2}(-)=$ "approve", $K_{2}(+)=$ "boycott" $]$, plus their mirror images with respect to $\beta=0.5$ :

$$
\begin{gathered}
\left.\left[\beta(\text { safe })=1-\beta_{0}, \beta \text { (dangerous }\right)=0.5 ; K_{1}\left(1-\beta_{0}\right)=\text { "approve", } K_{1}(0.5)=\text { "boycott" }\right] \\
{\left[\beta(\text { safe })=\beta(\text { dangerous })=1-\beta_{3} ; K_{1}\left(1-\beta_{3}\right)=\text { "test" and } K_{2}(-)=\text { "boycott", } K_{2}(+)=\text { "approve" }\right]}
\end{gathered}
$$

If the stakeholder is quasi-clairvoyant, however, the pooling equilibrium unravels. To see this, note that in this case a safe firm's data could have precision $\beta_{3}$ meanwhile a firm holding a dangerous activity would never be able to credibly commit not to supply a distorted test of accuracy $1-\beta_{3}$. Studying the report received would then yield the stakeholder an expected payoff

$$
\mu \beta_{3} \mathrm{G}+(1-\mu) \beta_{3} \mathrm{~B}-\mathrm{t}(\beta)<0
$$

when $\mathrm{K}_{2}(+)=$ "boycott" and $\mathrm{K}_{2}(-)=$ "approve", or

$$
\mu\left(1-\beta_{3}\right) \mathrm{G}+(1-\mu)\left(1-\beta_{3}\right) \mathrm{B}-\mathrm{t}(\beta)<0
$$

if $\mathrm{K}_{2}(+)=$ "approve" and $\mathrm{K}_{2}(-)=$ "boycott". The only possible candidates for an equilibrium are thus the two separating outcomes

$$
\begin{aligned}
& {\left[\beta(\text { safe })=\beta_{0}, \beta(\text { dangerous })=0.5 ; \mathrm{K}_{1}\left(\beta_{0}\right)=\text { "approve", } \mathrm{K}_{1}(0.5)=\text { "boycott"] },\right. \text { and }} \\
& {\left[\beta(\text { safe })=1-\beta_{0}, \beta(\text { dangerous })=0.5 ; \mathrm{K}_{1}\left(1-\beta_{0}\right)=\text { "approve", } \mathrm{K}_{1}(0.5)=\text { "boycott"] } .\right.}
\end{aligned}
$$

One interesting implication of these findings is that a looser regulatory context where potential polluters can delude external stakeholders does not necessarily involve hazier disclosures. The quality of reports might actually go up (perhaps surprisingly) when the stakeholder is quasiclairvoyant, because the safe firm has then no other choice than to distinguish itself from a dangerous one by providing highly accurate (and expensive) data.

Suppose now that holding a dangerous industrial activity entails greater revenues, i.e. that $\mathrm{G}<\mathrm{B}$. If the potential polluter cannot lie or the stakeholder is clairvoyant, then the only possible equilibrium under this payoff structure is a pooling one, since a safe firm cannot credibly signal its goodwill ${ }^{12}$.

\footnotetext{
${ }^{12}$ It appears that no pure-strategy equilibrium exists when $G<B$, the strategy $B(\cdot)$ is free, and the stakeholder is
} 
In this case a regulator who favors separation between safe and harmful activities might want to enforce substantial ex post penalties on the dangerous firm; by the above analysis the fine $t$ would then have to be set so that $\mathrm{G}>\mathrm{B}-t$.

Returning to the context of section 3 , where $\mathrm{G}>\mathrm{B}$, the potential polluter cannot lie and the stakeholder is quasi-clairvoyant, we shall finally examine some policy issues relating to the opportunity of mandatory standards and the use of taxes and subsidies.

\section{- Mandatory standards for environmental disclosure}

In this paper mandatory standards can be defined as the imposition of a floor level $\underline{\beta}>0.5$ on the precision of reports. Let $\beta_{4}=\max \left\{\beta_{3}, \underline{\beta}\right\}$ denote the precision level that is now associated with a pooling equilibrium. If $\mathrm{W}_{\text {sep }}>\mathrm{W}_{\text {pool }}$ but pooling is the occurring outcome, then a benevolent regulator would clearly want to reset $\underline{\beta}$ sufficiently higher than $\beta_{3}$ so that a safe firm finds it attrative to signal the nature of its activity. The reverse is true in the opposite case where $\mathrm{W}_{\text {sep }}<\mathrm{W}_{\text {pool }}$ but the separating outcome prevails; however, putting lower standards $\underline{B}$ may not suffice to induce pooling and the regulator may need to use other instruments as well.

\section{- $\quad$ Taxes and subsidies}

Let us consider the effect of adding an amount T to the stakeholder's cost of analysis $\mathrm{t}(\cdot)$, a negative $\mathrm{T}$ being interpreted as a subsidy and a positive $\mathrm{T}$ as a tax. According to figure 2 and the second proposition, a subsidy of this sort would increase the likelihood of a pooling equilibrium whilst a tax would do the opposite. Therefore, if the more precise data of a signalling equilibrium is always socially desirable, then the regulator should tax independent counter-expertise by the stakeholder.

Considering now the impact of changing the data production cost $\mathrm{f}(\cdot)$ by adding a fixed amount $\mathrm{F}$ to it, it appears that a subsidy $\mathrm{F}<0$ would decrease, and tax $\mathrm{F}>0$ increase, the precision levels associated with both the pooling and the separating outcomes. If the regulator wants to depart from a separating equilibrium or to improve the quality of information in a pooling situation, then a subsidy to environmental reporting would be the right instrument to use.

quasi-clairvoyant. 


\section{CONCLUDING REMARKS}

There are circumstances under which an informed potential polluter cannot credibly document and disclose all his information to every external stakeholder. This paper examined the factors that might influence the quality of voluntary disclosures in this case. We modelled quality as the precision (in the usual sense of decision analysis) of a test that would be based on the delivered data. Then we brought up specific features of the stakeholder, such as her mood (confident or worried), her perceptiveness (clairvoyance or quasi-clairvoyance), and her cost of analyzing environmental reports, along with more customary items like the cost of producing and delivering information. Our main results (propositions 1 and 2) predict that voluntary disclosures would be very vague (thus inexpensive) when the stakeholder is already confident, but that the necessity to reassure a quasiclairvoyant yet worried stakeholder could force a firm to invest in accurate environmental reporting. These results and the model itself yield a number of implications regarding informational regulation, some of which are sketched in sections 3 and 5. We showed, for example, that subsidies to environmental reporting are an imperfect substitute for mandatory disclosure, because they might allow a dangerous firm to match the quality of the information expected from a safe firm and so look ex ante as if its current activity were harmless.

Our modelling approach is rather broadlooking and bridges the literatures on signalling and persuasion games. The model thus seems to fit a wide range of situations and suggests several possible extensions. A valuable one would be to add a competing source of information, another one to investigate the formation of prior beliefs by the stakeholder, and another one to consider mixed strategies as an answer to ambiguity or radical uncertainty. The price to pay for this flexibility, however, is to have a model that may look too abstract in some settings. An awaited remedy to this would be to formally relate the various levels of the above precision parameter $\beta$ to concrete attributes of environmental reports. 


\section{References}

1. S. Afsah, B. Laplante, and D. Wheeler, Controlling industrial pollution: a new paradigm, World Bank, Policy Research Department, Working Paper no. 1672, 1996.

2. R. Bowden, "Statistical games and human affairs." Cambridge University Press, Cambridge, UK, 1989.

3. L. Bui and C. Mayer, Regulation and capitalization of environmental amenities: evidence from the toxics release inventory in Massachusetts, unpublished manuscript, Boston University, 2000 .

4. K. Cho and D. Kreps, Signalling games and stable equilibria, Quart. J. Econ. 102, 179-221 (1987).

5. Crawford and J. Sobel, Strategic information transmission, Econometrica 50, 1431-1451 (1982).

6. D. Diamond, Optimal release of information by firms, J. Finance 40, 1071-1094 (1985).

7. X. De Groote, Information disclosure and technology choice, INSEAD W. P., Fontainebleau, France, 1992.

8. R. Dye, Disclosure of non-proprietary information, J. Accounting Res. 23, 123-145 (1985).

9. M. J. Fishman and K. M. Hagerty, The optimal amount of discretion to allow in disclosure, Quarterly J. Econom. 105, 427-444 (1990).

10. D. Fudenberg and J. Tirole, "Game Theory.” MIT Press, Cambridge, MA, 1991.

11. S. Grossman, The informational role of Walrasian and private disclosure about the product quality, J. Law Econom. 24, 461-483 (1981).

12. P. Hughes, Signaling by direct disclosure under asymmetric information, J. Accounting Econom. 8, 119-142 (1986).

13. M. Khanna, W. R. Quimio, and D. Bojilova, Toxic release inventory: A policy tool for Environmental protection, J. Environ. Econom. Management 36, 243-266 (1998).

14. M. Khanna, W. R. Quimio, and D. Bojilova, Information as regulation: The effect of Community right-to-know laws on toxic emissions, J. Environ. Econom. Management 35, 124 (1997).

15. P. R. Kleindorfer and E. W. Orts, Informational regulation of environmental risks, Risk 
Analysis 18, 155-170 (1998).

16. T. Lewis and M. Poitevin, Disclosure of information in regulatory proceedings, J. Law, Econom. and Organization 13, 50-73 (1997).

17. P. Milgrom, Good news and bad news: representation theorems and applications, Bell J. Econom. 12, 380-391 (1981).

18. P. Milgrom and J. Roberts, Relying on the information of interested parties, Rand J. Econom. 17, 18-32 (1986).

19. M. Okuno-Fujiwara, A. Postlewaite, and K. Suzumura, Strategic information revelation, Rev. Econom. Stud. 57, 25-47 (1990).

20. H. Shin, News management and the value of firms, Rand J. Econom. 25, 58-71 (1994).

21. B. Sinclair-Desgagné, Environmental risk management and the business firm, in "The International Yearbook of Environmental and Resource Economics 2001/2002” (T. Tietenberg and H. Folmer, Eds.) Edward Elgar, Northampton, MA, 2001 (forthcoming).

22. P. Stocken, Credibility of voluntary disclosures, Rand J. Econom. 31, 359-374 (2000).

23. S. Teoh and C. Hwang, Nondisclosure and adverse disclosure as signals of firm value, Rev. Financial Stud. 4, 283-313 (1991).

24. T. Tietenberg and D. Wheeler, Empowering the community: Information strategies for pollution control, in "Frontiers of Environmental Economics" (H. Folmer, H. L. Gabel, S. Gerking and A. Rose, Eds.) Edward Elgar, Northampton, MA, 2001.

25. S. Titman and B. Trueman, Information quality and the valuation of new issues, J. Accounting Econom. 8, 159-172 (1986).

26. B. Trueman, Why do managers voluntarily release earnings forecasts?, J. Accounting Econom. 8, 53-71 (1986).

27. R. E. Verrecchia, Discretionary disclosure, J. Accounting Econom. 5, 179-194 (1983).

28. Wagenhofer, Voluntary disclosure with a strategic opponent, J. Accounting Econom. 12, 341-363 (1990). 


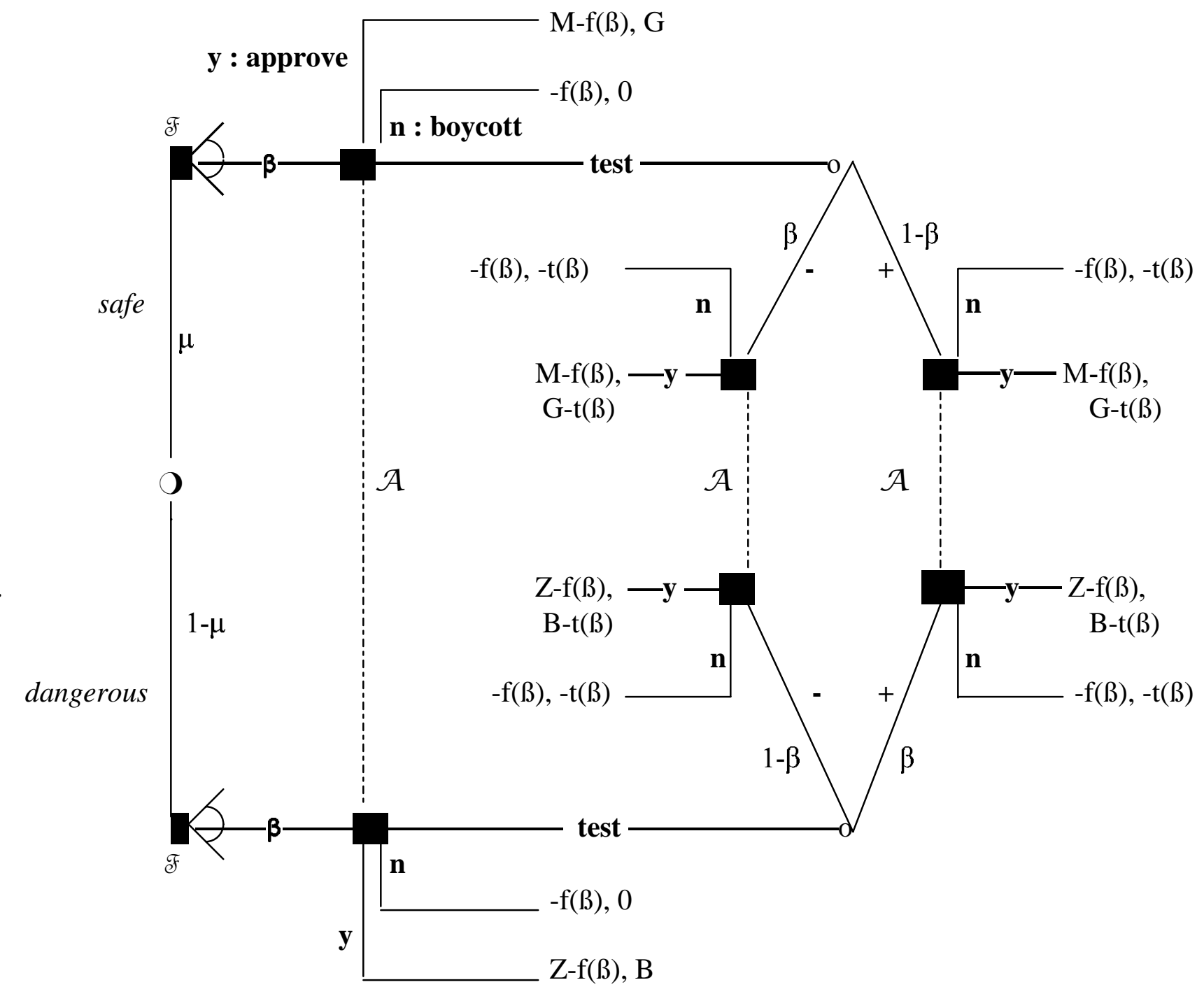

FIG. 1. The game in extensive form. 


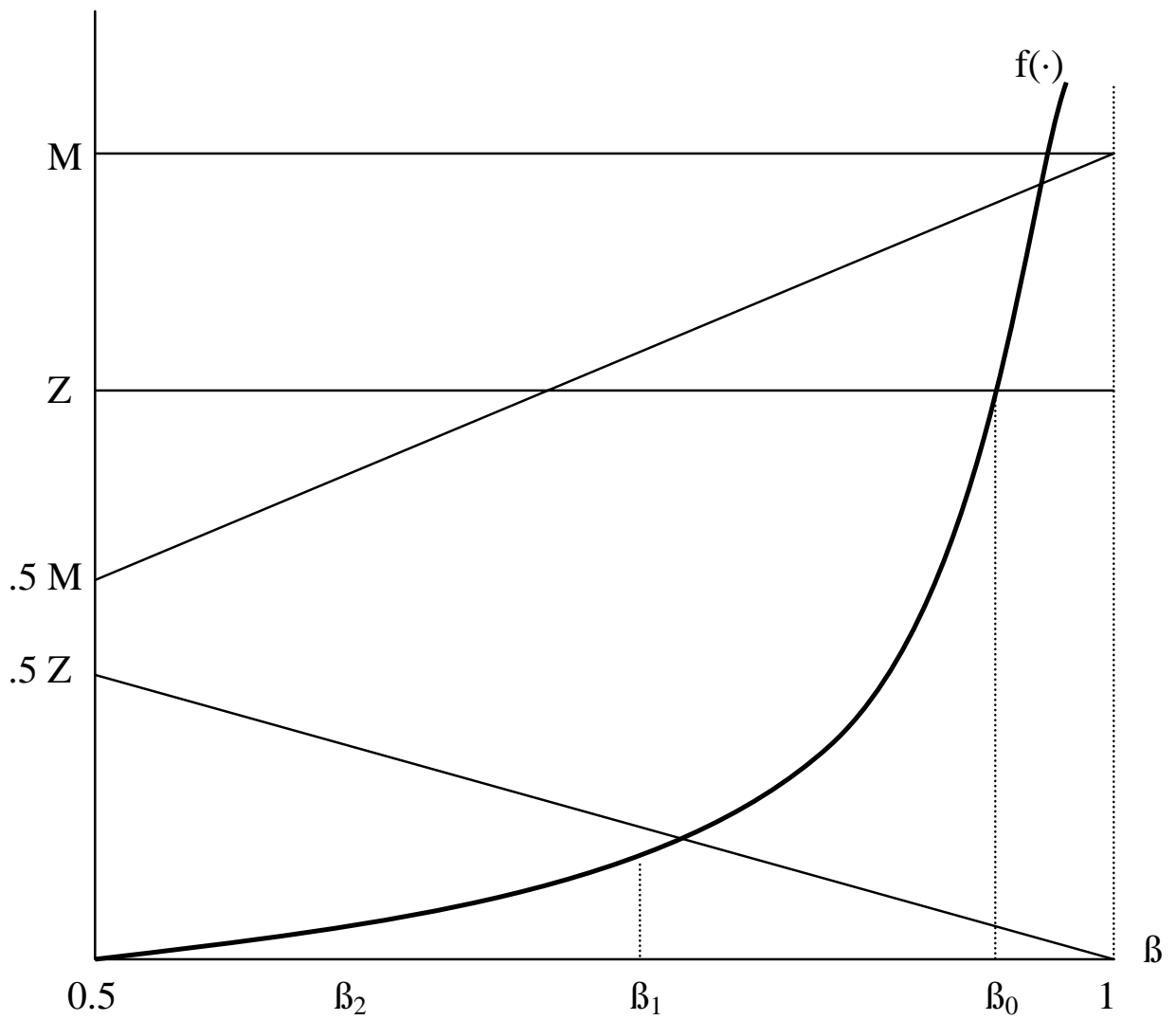

FIG. 2. Precision thresholds. 


\section{Liste des publications au CIRANO *}

\section{Cahiers CIRANO / CIRANO Papers (ISSN 1198-8169)}

99c-1 Les Expos, l'OSM, les universités, les hôpitaux : Le coût d'un déficit de 400000 emplois au Québec — Expos, Montréal Symphony Orchestra, Universities, Hospitals: The Cost of a 400,000-Job Shortfall in Québec / Marcel Boyer

96c-1 Peut-on créer des emplois en réglementant le temps de travail? / Robert Lacroix

95c-2 Anomalies de marché et sélection des titres au Canada / Richard Guay, Jean-François L'Her et Jean-Marc Suret

95c-1 La réglementation incitative / Marcel Boyer

94c-3 L'importance relative des gouvernements: causes, conséquences et organisations alternative / Claude Montmarquette

94c-2 Commercial Bankruptcy and Financial Reorganization in Canada / Jocelyn Martel

94c-1 Faire ou faire faire : La perspective de l'économie des organisations / Michel Patry

Série Scientifique / Scientific Series (ISSN 1198-8177)

2001s-16 Marriage Market, Divorce Legislation and Household Labor Supply /

Pierre-André Chiappori, Bernard Fortin et Guy Lacroix

2001s-15 Properties of Estimates of Daily GARCH Parameters Based on Intra-Day

Observations / John W. Galbraith et Victoria Zinde-Walsh

2001s-14 A Ricardian Model of the Tragedy of the Commons / Pierre Lasserre et Antoine Soubeyran

2001s-13 Carbon Credits for Forests and Forest Products / Robert D. Cairns et Pierre Lasserre

2001s-12 Estimating Nonseparable Preference Specifications for Asset Market Participants / Kris Jacobs

2001s-11 Autoregression-Based Estimators for ARFIMA Models / John W. Galbraith et Victoria Zinde-Walsh

2001s-10 Heterogeneous Returns to Human Capital and Dynamic Self-Selection / Christian Belzil et Jörgen Hansen

2001s-09 Return to a High School Diploma and the Decision to Drop Out: New Evidence from Canada / Daniel Parent

2001s-08 Leader and Follower: A Differential Game Model / Hassan Benchekroun et Ngo Van Long

2001s-07 Emission Taxes and Standards for an Asymmetric Oligopoly / Ngo Van Long et Antoine Soubeyran

* Vous pouvez consulter la liste complète des publications du CIRANO et les publications elles-mêmes sur notre site Internet à l'adresse suivante :

http://www.cirano.umontreal.ca/publication/documents.html 